\title{
Short Bowel Syndrome
}

National Cancer Institute

\section{Source}

National Cancer Institute. Short Bowel Syndrome. NCI Thesaurus. Code C99059.

Malabsorption that results from the removal of a large segment of the small intestine or, less frequently, from the complete dysfunction of a large portion of the small intestine. Signs and symptoms include diarrhea, steatorrhea, and weigh loss. 